\title{
Poesia e crítica de poesia hoje: heterogeneidade, crise, expansão ${ }^{1}$
}

\author{
CELIA PEDROSA I
}

A

S QUESTÕES que mobilizam a crítica de poesia contemporânea podem ser compreendidas como efeito do enfrentamento da heterogeneidade da cena literária. Dessa decorre, desde logo, a inevitabilidade de uma discussão radical sobre o valor mesmo das noções de poesia e de crítica. E ainda o reconhecimento de que, ao contrário de referir-se apenas a um vínculo unívoco entre uma demarcação cronológica e um conjunto de autores e obras, a situação de contemporaneidade serve para deixar em aberto o sentido e os limites da prática poética e de sua inscrição temporal.

Na verdade, essa abertura já era apontada como fundamental ao complexo processo de avaliação da modernidade da arte e do pensamento como correlação de forças contraditoriamente históricas e anti-históricas, direcionada para a problematização da ideia mesma de presente. São clássicas, nesse sentido, as reflexões empreendidas por Octavio Paz (2013), em Os filhos do barro, e por Walter Benjamin (1986), em "Sobre o conceito de história". Mais recentemente, Jacques Rancière (1995b, p.128-9), em "Transportes da liberdade”, por exemplo, vai atualizar esse processo, considerando que apresentar uma palavra diante da face do tempo é, antes de mais nada, operar um trabalho sobre o presente, de modo a possibilitar "o acontecimento do encontro livre e aleatório das palavras e das coisas".

Tal perspectiva não entra em contradição com o enfoque específico, neste texto, da crítica de poesia produzida a partir da passagem da década de 1970 para a de 1980. Ao contrário, ele se justifica porque localizamos nesse período justamente a emergência - em seu duplo valor de irrupção e urgência, conforme sugere Reinaldo Ladagga (2006) - de um uso insistente da noção de contemporâneo, que propomos associar a uma lacuna classificatória, a uma incerteza de parâmetros de produção e avaliação. Compreendidas ora positiva, ora negativamente, essa lacuna e essa incerteza desafiam tanto a crítica quanto as reflexões filosófica e histórica que a alimentam.

Assim, é a partir desse novo fin-du-siècle que vai ser proposto o termo pós- moderno e pouco a pouco ser abandonado seu viés classificatório, para se pensar a produção poética como contemporânea, referindo-a com isso a um presente em que, para o mal ou para o bem, os valores antes considerados idealmente 
modernos começam a se fragilizar. Assim ocorre com a demanda de autonomia, experimentalismo formal e ruptura com a tradição, associada à crença numa pedagogia utópica da resistência, em que o estético se articularia idealmente com o político. Essa demanda e essa crença, legitimadas pela pretensão ao universal e ao universalizante - dialeticamente harmonizados com o nacional -, motivavam uma luta pela hegemonia em torno do qual se definiam grupos e bandeiras claramente antagônicos. A partir de fins dos anos 1970 tais motivações excludentes e hierarquizantes passam a ser mais explicitamente reconhecidas como autoritárias e/ou infrutíferas.

Essa mudança está associada a uma dinâmica social em que o empenho revolucionário se esgota e dá lugar a formas várias de inscrição numa democracia neoliberal globalizada, regida pela lógica do mercado, que valoriza estratégias de convívio e negociação. Nela vão ganhando força crescente as indústrias da informação e da cultura, ambas muito frequentemente experimentadas como puro entretenimento. Impulsionada pelo duplo e contraditório efeito do desenvolvimento tecnológico, que tanto estimula a diversificação de lugares e meios de produção quanto sua circulação uniformizadora, essa dinâmica vai contribuir para a equivalência, em princípio também democratizante, do artístico ao cultural, e para o esvaziamento do valor pedagógico da arte.

Nesse quadro, a produção poética, como já dito, passa a se caracterizar também pela pluralidade de discursos e tendências. Mas nenhum deles consegue se tornar hegemônico, principalmente em função da perda de legitimidade das noções de excepcionalidade da arte e do artista, seja em suas manifestações institucionais ou marginais, seja nas eruditas ou populares. A esse respeito, é importante referir aqui a postura de Antonio Candido, o mais importante crítico literário brasileiro do século XX, responsável pela sistematização do cânone modernista e moderno. Em pequeno mas instigante artigo sobre "A literatura brasileira em 1972", Candido (1979) se debruça sobre esse momento, surpreendendo-se com sua pluralidade e sua diferença em face do valorizado até então, apontando a ausência de grandes nomes e obras-primas modelares, sem no entanto fazer disso motivo de lamentação. Ao contrário, lembra Mário de Andrade para sustentar o maior interesse da produção regular de boa qualidade para a avaliação das forças em jogo em todo contexto literário e histórico. E, acima de tudo, sugere a falibilidade de seus próprios parâmetros, ao considerar que o cenário heterogêneo anima, inquieta, aguça o desejo de compreender "o destino da arte e da literatura, envolvidas no turbilhão da mudança rápida de práticas e valores" (Candido, 1979, p.21-3). ${ }^{2}$

Atentando para esse desafio, propomos avaliar a crítica de poesia em função do modo como, em face da produção contemporânea, ela coloca em circulação as ideias de expansão e de crise. Quanto a isso, podemos identificar, grosso modo, três tendências. A primeira definir-se-ia pela compreensão do contemporâneo como pós-moderno, e desse como efeito de uma crise do moderno - crise aí 
considerada sinônimo de esgotamento da originalidade e da representatividade que o poético antes exercitava através de obras-primas exemplares em termos simultaneamente nacionais e universais. A segunda, em princípio oposta, usaria também a categoria de pós-moderno, mas para endossar esse esgotamento do que considera autoritário na noção moderna de arte; e em consequência aceitar a convivência plural em si mesma como índice de vitalidade.

Em nosso entender, no entanto, ambas acabam por afirmar uma compreensão homogeneizante da pluralidade, vendo-a ora negativa, ora positivamente - mas de todo modo se abstendo de nela identificar forças de diferenciação que complexifiquem o campo da contemporaneidade. Tal orientação comum pode ser associada ao compartilhamento também de uma concepção de crise como resultado de uma força externa, circunstancial e negativa - a ser evitada - sobre a plenitude de uma forma e de um sentido já plenamente realizados ou na pluralidade mesma da vida literária e cultural.

Nessas perspectivas, percebe-se a dificuldade de enfrentamento do heterogêneo e de fazer disso oportunidade de questionar generalizações e discutir a partir de tensões, incertezas. A contrapelo de ambas, identificamos na reflexão sobre o contemporâneo a constituição de um lugar alternativo a partir justamente do uso não idealista da ideia de crise. Esse uso implicaria um movimento de constante reescritura da modernidade, que Jean-François Lyotard (1997) chamou de perlaboração - segundo noção tomada de empréstimo à definição freudiana dos mecanismos psicoafetivos da memória. Por essa via, a modernidade, em seu caráter fundador - fundação constituída de contradições e paradoxos -, se manifestaria sempre como acontecimento, como pergunta e busca sobre o que significa ser presente, sobre o que é o presente, e no presente é ausência e lacuna, sobre o que tem valor de presença no que já não é e no desconhecido que está por vir.

Essa proposta de reescritura atualiza na contemporaneidade dita pós-moderna as leituras da modernidade que já apontamos em Octavio Paz, Walter Benjamin e Jacques Rancière, na contracorrente de suas formas disfóricas ou eufóricas de passadismo e presentismo. Vários são seus efeitos produtivos. $\mathrm{Na}$ base de todos eles está a revisão de dicotomias com as quais a concepção de arte moderna foi canonizada: entre modernismo e modernidade, entre arte e cultura, entre tradição e ruptura, entre experimentação e experiência, entre forma e força.

Sob essa perspectiva, é bastante representativa a reflexão de Paul de Man (1999). Propondo-se também a substituição da dicotomia pela contradição irresolvida, ele vai rever, por exemplo, o formalismo atribuído à poesia de Mallarmé, na qual passa a enfatizar a tensão entre experimentação e referencialidade, subjetividade e objetividade, afetividade e racionalismo construtivo. É mais significativo ainda que Man desenvolva essa releitura da modernidade a partir justamente do enfoque da relação entre "Crítica e crise", conforme intitula um de seus ensaios. Tomando como ponto de partida a análise já clássica de Mallarmé 
sobre a crise do verso, vai denunciar as contradições que subjazem à arrogância com que a crítica moderna se instituíra por oposição às ilusões idealistas do romantismo. E enxergar, no ensaio mallarmaico, a capacidade de colocar em crise a sua própria prática de poesia, em lugar de simplesmente confirmá-la por oposição à tradição.

Num cenário em que, como vimos, a pluralidade é valorizada contra o cânone moderno, ou, ao contrário, recusada em nome da importância insuperável de procedimentos modernos de transgressão e ruptura, é sintomático que o interesse por Mallarmé esteja funcionando, através do uso da noção de crise, de modo a evidenciar a heterogeneidade que é o próprio móvel da modernidade e, em consequência, a estimular na crítica de poesia uma perspectiva que permite evitar essas homogenizações e antagonismos simplistas.

Além disso, tal recontextualização do poeta ocorrendo num momento que vem sendo caracterizado pelo retorno do verso, inscreve-o e à sua modernidade numa temporalidade anacrônica, que desestabiliza a oposição entre início e fim, assim como contribui também para desassociar sua reflexão da ideia de fim do verso. Do mesmo modo, contribui para problematizar na poesia contemporânea essa ideia mesma de retorno do verso e da discursividade, assim como sua associação a um retorno da experiência subjetiva.

Em lugar disso, passamos a ter em conta, ao contrário, o caráter dramático da vontade de poesia desde a modernidade, na tensão entre empenho de singularidade formal e demanda de valor social, seja ela marcada pela ausência ou pela presença ilocutória do eu. Pois percebe-se então que a ideia de retorno supõe a possibilidade de um total apagamento ao qual se sucederia de novo uma presença originariamente plena, e que a valorização do estado de crise é mesmo o fundamento da poesia moderna e implica, ao contrário, a necessidade de pensar a relação inextricável entre presença e ausência, estabilidade e instabilidade, efetividade e incerteza como constituintes de toda forma - no verso, no poema, na experiência de subjetivação através deles performada. Em outras palavras, pensar toda forma como acontecimento da crise, habitada pelas forças desestabilizantes do informe, na contracorrente da polarização entre forma e força.

Revisitando a modernidade a partir da vontade de crítica a essa mesma polarização, Martin Jay (2003) vai atualizar o pensamento de George Bataille para associar a produtividade dessa tensão à importância que adquire na poética de Rimbaud a figura da multidão. Jay (2003) nos sugere compreender essa figura - que não por acaso tem papel fundamental na discussão ética e política de nossa contemporaneidade - como efeito de uma relação entre forma e força que dá visualidade háptica e heterogênea ao vínculo entre poesia e vida social que desafia identidades unívocas e classificatórias, assim como as célebres oposições que circunscreveram a leitura do poeta.

Essa perspectiva vai desestabilizar também, em consequência, a já tradicional oposição entre o vitalismo rimbaudiano e o formalismo mallarmaico, de 
grande importância na tradição crítica da poesia moderna. Jacques Rancière (1995a), que empreendeu a releitura desse vitalismo no ensaio "As vozes e os corpos", onde focaliza a relação entre corpo e letra na poesia de Rimbaud, alcança efeito ainda mais instigante quando enfrenta o mito do formalismo mallarmaico, no livro Mallarmé. La politique de la sirène (Rancière, 2006). Aí, antes de mais nada, questiona a obscuridade e o hermetismo que são atribuídos à sua poesia como consequência incontornável de seu teor antirrepresentativo, autorreflexivo, autônomo e resistente.

A essas qualidades o filósofo vai contrapor a de uma poesia a bem da verdade difícil-mas de uma dificuldade decorrente da necessidade de romper o convencionalismo que pode esterilizar igualmente o mais banal e o mais sublime; dificuldade análoga à vivida por todo poeta e toda época, e intrínseca à relação entre um e outra. Detendo-se também no ensaio sobre a crise de vers, Rancière (2006, p.12-13) vai considerar que, para abordar a simples dificuldade da obra do poeta, deve-se perceber que ela "obéit à une poétique exigeant qui répond elle'même à une conscience aigüé de la complexité d'un moment historique et de la manière dont les 'crises de vers' s'y nouaiente à la 'crise idéale' et à la 'crise sociale". Segundo ele, a escritura em crise do poema mallarmaico - a contrapelo do "mutismo tagarela da voz" - constituiria um acontecimento vivo, dotado da potência dos discursos emanáveis de qualquer boca (ibidem, p.90), apto a evitar não só o mal da incompreensão, mas também, e principalmente, o mal da compreensão rápida e, nela, o da apropriação ideológica da vontade de ser comum (ibidem, p.107).

Como se vê, a forte presença de Mallarmé no discurso filosófico implica uma opção por pensar a modernidade e a contemporaneidade como lugares mesmo de um movimento indisciplinado de expansão e crise da coesão cronológica da temporalidade, bem como da coesão do discurso poético e da subjetivação nele performada e, ainda, dos modos de neles pensar a relação entre empenho de singularidade e de comunidade. A esse respeito, é bem sugestivo constatar que, no ensaio citado, Rancière atribui à contemporaneidade de Rimbaud um entrelugar anacrônico, desajustado, entre uma velha e uma nova história; e que desajuste semelhante seja identificado por Giorgio Agamben (2011) como chave da modernidade radical de Mallarmé. ${ }^{3}$

Essa potência desestabilizante é reafirmada e intensificada em outros modos e contextos de sua recepção. É o que ocorre quando nos damos conta de que, apesar da canonização de sua poesia, na qual é fundamental inclusive a figura do poeta-crítico, seus principais ensaios não tinham até há pouco ampla circulação em língua portuguesa. E quando percebemos então que não pode ser vista como mera casualidade a ocorrência quase simultânea no Brasil e em Portugal hoje de um movimento de tradução e publicação justo do ensaio de Mallarmé sobre a crise do verso. De fato, no Brasil, Ana Maria Alencar (2007) publica "Crise do verso", na prestigiada revista de poesia Inimigo Rumor, e 
Fernando Scheibe (2010), "Crise de verso", em coletânea de ensaios do poeta (2010). Em Portugal, Rosa Martelo e Pedro Eiras (2012) também se dedicam a essa tarefa, intitulando de Crise de versos sua tradução, à qual destinam um prestigioso volume exclusivo.

Nesse sentido, vai ser bastante significativo também que esse interesse comum pelo ensaio produza três versões diferentes em português para seu título original e francês: "crise do verso", "crise de verso", "crise de versos" - nisso mesmo se efetivando um vínculo entre expansão de leitura e crise de sentido que potencializa a heterogeneidade de efeitos no uso da língua francesa e em sua leitura em português. É igualmente significativo o uso desse jogo entre o comum e o diverso para uma avaliação da cena brasileira atual, como propõe com acuidade o poeta e crítico Marcos Siscar (2010). Lembrando a associação tradicional da expressão "crise do verso" à ideia de fim $d o$ verso, aponta agora para a importância de traduzir o de do título francês também para o português de. Segundo ele, essa opção indicaria a crise como constitutiva mesmo do verso enquanto forma constantemente exposta a forças de desestabilização tanto da sintaxe considerada própria à poesia e da considerada própria à linguagem prosaica, quanto principalmente dos modos convencionais de pensar a oposição entre uma e outra (Siscar, 2010). E ressalta, desde Mallarmé, e a partir mesmo de sua poesia, a sobrevivência do verso, a expansão de seus limites convivendo com o que em princípio provocaria sua crise, como ocorre com o verso livre e o poema em prosa, se compreendidos na heterogeneidade de suas manifestações.

O caráter intempestivo dessa discussão sobre usos e efeitos da forma-verso em Mallarmé e a partir dele fica mais claramente provocante se levamos em conta a identificação genérica da contemporaneidade pós-moderna como palco de reivindicações libertárias anticanônicas associadas à reaproximação antiformalista da experiência subjetiva individual e coletiva. No caso brasileiro, isso vai se manifestar no início do período aqui referido, pela demanda de uma poesia jovem, aventureira, "rimbaudiana", em que a presença ilocutória do eu era índice de um espontaneísmo ingênuo, pois contraditoriamente tecido de valores associados à contracultura beat e à marginalidade nacional, extraídos do contato com o cotidiano prosaico contaminado por mitos da indústria cultural.

Mallarmé era então mais uma vez - como já o fora no modernismo - rejeitado como emblema de uma modernidade isolacionista, bibliotecária - função na época atribuída também a João Cabral de Melo Neto, cuja obra se abre com uma epígrafe extraída ao poeta, seu célebre verso "solitud, récif, étoile...". Embora fragilizada, não mais reivindicada explicitamente como bandeira de luta, tal rejeição ainda tem algum lugar na medida em que a associação entre pós-modernismo e culturalismo passou a legitimar uma outra reivindicação de proximidade entre literatura e vida, agora através do convívio com linguagens e práticas identitárias plurais, mas homogeneizadas, vinculadas a valores de raça, de gender, de subalternidade. 
E, no entanto, já naquele primeiro momento de antagonismo a potencialização paradoxal da presença intempestiva de Mallarmé pode ser localizada. E, entre outras situações, justamente no discurso crítico de Silviano Santiago (1978a), que desde cedo se distinguiu como precursor do processo de releitura do cânone moderno, e de valorização de uma pós-modernidade liberada de seus dogmas hierarquizantes. Lembremos, então, que em sua primeira coletânea de ensaios ele cunha o conceito de entrelugar, para nomear a prática de arte e de pensamento capaz de subverter dicotomias de toda ordem e operar justamente com a relação de expansividade e crise, sem síntese possível, aquém de toda dialética, entre o dominador e o dominado, o colonizador e o colonizado, o nacional e o estrangeiro, o tradicional e o inovador, o erudito e o popular.

São inúmeros e bastante reconhecidos os efeitos produtivos dessa elaboração conceitual, que atualiza a imagem modernista da fome antropofágica para a releitura da história da cultura e da literatura brasileira em sua relação com a tradição moderna ocidental, permitindo aproximar provocativamente Jorge Luis Borges, Eça de Queirós, Flaubert e Oswald de Andrade, entre outros. Para efeito de nossa abordagem, detemo-nos, nesse livro inaugural, no ensaio intitulado "O assassinato de Mallarmé". Nele, antes de mais nada, Silviano (1978b) vai relativizar polarizações e complexificar o campo de forças da cena literária, mostrando que as reinvindicações de espontaneísmo antiexperimental se inspiravam na poesia modernista de Oswald, tal como atualizada a partir da releitura crítica de seu manifesto antropófago feita justamente por Haroldo de Campos e seu grupo de poesia de vanguarda concretista - um dos discípulos de Mallarmé rejeitados pelos jovens poetas dos anos 70. Com discreta ironia, vai lembrar também que um dos aspectos distintivos mais importantes desse grupo, o interesse pela materialidade do livro e por formas alternativas de sua circulação, tinha sido pioneiramente manifestado por João Cabral de Melo Neto e depois transformado em procedimento comum pelos mesmos concretistas, fazendo-nos lembrar dos vínculos entre a poesia "pura" de Mallarmé e as inovações tecnológicas tão prosaicas da tipografia.

Além disso, ele aponta a tendência à estetização da sensibilidade marginal e sua forte inserção no sistema através do consumo da mass media. E conclui ressaltando seu caráter de manifestação anárquica e neorromântica de "eus ciclópicos e formidáveis", o assassinato de Mallarmé gerando então não uma saída, mas um impasse para a poesia do momento - impasse que lhe provoca o desejo de... "acreditar um pouco mais na cultura e nos livros" (Santiago, 1978b, p.189).

Tal perspectiva é reiterada em um segundo ensaio, "Singular e anônimo", do livro Nas malhas da letra (Santiago, 1989), no qual toma como ponto de partida a oposição entre essa poesia antimallarmaica e a de Ana Cristina Cesar. No entanto, na contracorrente de uma diretriz crítica por muito tempo dominante, não vai reafirmar essa oposição e fazer sua opção entre o espontaneísmo prosaico, mas egocêntrico, praticado pela maioria, e a elaboração sofisticada, 
mas capaz de adensar a figuração das relações entre linguagem, subjetividade e vida cotidiana, praticada por Ana Cristina.

Enfatizando a heterogeneidade poético-prosaica de sua poesia, entretecida de citação literária e prosaísmo oral e escrito, de conversas, diários e cartas, expressividade e mascaramento ficcional da afetividade, Silviano vai antes de mais nada evidenciar a impossibilidade e a inutilidade de optar por um ou outro desses polos. Embora não cite Mallarmé, recorre à tradição erudita moderna, através de referências a Baudelaire, Eliot, Valéry e Carlos Drummond de Andrade, para definir um paradigma de leitura alternativo ao expressivo/representativo e ao formal/ficcional, bem como à dicotomia entre ambos. Retomando a discussão sobre a oposição entre poesia fácil e difícil, travada entre Ana Cristina e seus companheiros de geração - e até hoje levantada -, Silviano vai considerar que todo poema é difícil e ao mesmo tempo sempre inclui um leitor que não se furte à travessia imprevisível rumo a um sentido desconhecido, ao longo da qual se afirma, desdobra e se põe em suspenso também a subjetividade do eu poético.

Essa ênfase na relação entre autor e leitor constitui um paradigma performativo de compreensão da singularidade paradoxal do discurso poético, baseada na relação ao mesmo tempo particularizada e anônima, indeterminada, estabelecida pelo uso dos pronomes pessoais. Nesse vínculo entre emissão e destinação, ausência e presença, o processo de subjetivação, como o verso, acontece como experiência inacabada, em que o impulso expansivo rumo ao destinatário, ao exterior indeterminado espacial e temporalmente do eu e do poema, não pode deixar de ser simultaneamente um movimento de crise.

Tal duplo valor ensina a perceber em seu caráter também duplo de expansão e crise a experiência cotidiana da conversa e do diálogo. E evidencia assim o simplismo de certo uso ainda bastante insistente das noções de coloquialidade e prosaísmo, legitimado pela demanda de adequação do poético a uma identidade homogênea de seu público. Na relação entre emissor e destinatário anônimo do poema, com o qual pode se identificar todo e qualquer leitor, se encenaria, ao contrário, uma experiência da convivência expansiva mas sempre lacunar entre o singular e o comum que o crítico vai nomear como cidadã, convidando a repensar as armadilhas das demandas pretensamente democráticas de legitimação social do poeta e do poema. ${ }^{4}$

Desse modo, Silviano não só se aproxima da leitura do paradoxo entre dificuldade e comunidade na poesia de Mallarmé por Rancière, como dá voz a uma forte inflexão do discurso filosófico e crítico contemporâneo, atento à questão do envio, da escuta, da multitude. Acreditamos que sua leitura influencia direta ou indiretamente os movimentos mais produtivos da crítica de poesia contemporânea no Brasil. Não por acaso, eles têm em comum, antes de mais nada, o interesse pela poesia de Ana Cristina Cesar, revisitada, desde os anos 1980 , por três gerações de críticos.

Não sendo nosso objetivo um levantamento exaustivo, enumeramos aqui 
aqueles que mais de perto exemplificam a perspectiva crítica que vimos ressaltando. Assim, Flora Süssekind (1995) será a primeira a retomar a leitura da poeta, nela focalizando a relação entre o uso de uma "retórica da conversação" e o jogo entre confissão e ficção que desdobra o sujeito poético em vozes várias e fragmentárias, que se apresentam como efeitos de escuta e leitura de vozes de origem e estatuto o mais vário - procedimento que vai identificar mais tarde também na poesia portuguesa de Adília Lopes (Süssekind, 2002). Ampliando seu corpus, Flora vai posteriormente apontar em vários prosadores e poetas contemporâneos procedimentos de desterritorialização que servem à expansão de limites formais, geográficos e sociais, e simultaneamente desestabilizam parâmetros "realistas" de identificação da relação entre literatura e experiência (Süssekind, 2005) e entre literatura e imagem visual. Já em ensaio mais recente, sobre "A imagem em estações”, Süssekind (2008) focaliza na poesia de Carlito Azevedo a realização exemplar da tendência da poesia contemporânea à hibridização do lírico com o narrativo e o dramático, nele servindo a uma dinâmica dissociativa e conflituosa, de expansão e parcelamento, dos processos de construção de imagens, tensionando mais uma vez o verbal e o visual, o discursivo e o figurativo.

Marcos Siscar (2011), além de desenvolver uma abordagem teórica sobre a ideia de crise no verso e na poesia, como vimos, vai voltar a abordá-la, à semelhança de Silviano Santiago, como móvel da relação dramática, intensa mas lacunar, simultaneamente desejante e fugidia, entre o sujeito poético e o destinatário-leitor na poesia de Ana Cristina Cesar. Diagnosticando mais um vez a pouca produtividade do antagonismo entre expressividade e elaboração formal, ressalta a importância de, em nosso momento de presença excessiva e narcísica do eu, avaliar e mobilizar a força ética e política dessa heterogeneidade dramaticamente endereçada dos "discursos do coração", que remete ao pré-romantismo. Em âmbito mais amplo, nos vários ensaios reunidos em livro sob o título Poesia e crise (Siscar, 2010), revê consensos sobre poetas canônicos, como João Cabral e Haroldo de Campos, ao mesmo tempo que atenta para a pluralidade de dicções contemporâneas, nelas enxergando modos heterogêneos de enfrentamento das ruínas da tradição e da poesia como promessa.

Perspectiva semelhante, e complementar, pode ser identificada no trabalho desenvolvido pela estudiosa argentina Florencia Garramuño sobre a literatura brasileira, especialmente a produzida a partir dos anos 1980. Pois se a crítica de Marcos Siscar nos apresentou a formulação da ideia de crise, em Florencia fomos encontrar a de expansã $0^{5}$ - da aproximação comparativa de ambos tirando elementos para a articulação dessas noções e delas à ideia mesma de contemporaneidade. Florencia tem nos ensaios de Silviano Santiago uma de suas principais referências, ao lado da poesia de Ana Cristina Cesar, Carlito Azevedo, Ricardo Domeneck e Marília Garcia, e inclusive também a de Marcos Siscar. Mas o mais importante aqui é registrar que a partir dessas e de outras leituras, ela vai concluir sobre a pertinência do conceito de campo expansivo, que toma emprestado 
a Rosalind Krauss (1983). E que por meio dele, e à semelhança do que propõe Marcos Siscar, ao mesmo tempo apresenta uma tendência importante da produção literária contemporânea e reivindica os abalos produtivos que seu reconhecimento deve provocar no discurso crítico. Assim, identifica a provocante recorrência da heterogeneidade em textos que rompem limites de gênero, linguagem e cultura, hibridizando fragmentária e inacabadamente real e ficcional, artístico e científico, verbal e visual, prosa e poesia.

Desse quadro, Florencia vai depreender não apenas a necessidade do uso de um enfoque comparativo, mas a de repensar metodologias comparativas fundamentadas no uso de noções e procedimentos analíticos vinculados restritamente às ideias de unidade e especificidade autoral, textual, literária, nacional. Avançando a compreensão desses efeitos teórico-críticos, podemos concluir que, como na perlaboração da modernidade provocada pela releitura da crise de verso mallarmaica, eles implicam uma concepção mesma de contemporaneidade também feita de expansão e crise, aberta a movimentos anacrônicos que incitam a percepção do heterogêneo tanto no presente quanto no passado, redimensionando a história literária e cultural.

Compartilhando com Florencia a citação de Kenneth Reinhard (1995), que ela escolhe para finalizar seu ensaio, consideramos então que a relação entre poesia e crítica de poesia hoje propõe a incontornabilidade de uma prática de leitura comparativa que

otherwise than comparison [...] a mode of reading logically and ethically prior to similitude, a reading in which texts are not so much grouped into "families" defined by similarity and difference, as into neighborhoods determined by accidental contiguity, genealogical isolation and ethical encounter.

Notas

1 Este texto foi originalmente escrito para publicação no livro Crítica de poesia: tendências e questões. Brasil-Portugal (Pedrosa; Alves; Júdice, 2014).

2 Sob essa perspectiva avaliei a importância da contribuição desse crítico em meu livro Antonio Candido: a palavra empenhada (Pedrosa, 1994).

3 Devo a indicação da citação de Mallarmé por Giorgio Agamben a Raul Antelo (2014) que, de novo, não por mera coincidência, escreve texto ainda inédito sobre a recepção latino-americana de Mallarmé, mas focalizando as primeiras décadas do século XX.

4 Abordei a importância do endereçamento como procedimento poético e noção crítica a partir dos anos 80 do século XX no ensaio "Poesia, crítica, endereçamento" (Pedrosa, 2015).

5 Também foi importante nesse sentido a leitura posterior de No contemporáneo: arte e escritura expandidas, de Roberto Corrêa dos Santos e Renato Rezende (2011). 
AGAMBEN, G. O autor como gesto. In: . Profanações. Lisboa: Cotovia, 2006. . O reino e a glória. São Paulo: Boitempo, 2011.

ALENCAR, A. M. (Trad.) Mallarmé. Crise do verso. Inimigo Rumor, Rio de Janeiro, n.20, 2007.

ANTELO, R. Mallarmé e o lugar. In: Palestra na Escola Brasileira de Psicanálise, seção Santa Catarina, jun. 2014.

BENJAMIN, W. Obras escolhidas v.1. São Paulo: Brasiliense, 1986.

CANDIDO, A. A literatura brasileira em 1972. Arte em Revista. Anos 60, São Paulo, n.1, 1979.

CORREAA DOS SANTOS, R.; REZENDE, R. No contemporâneo: arte e escritura expandidas. Rio de Janeiro: Faperj/Circuito, 2011.

DERRIDA, J. O cartão postal. Rio de Janeiro: Civilização Brasileira, 2007.

GARRAMUÑO, F. La literatura en un campo expansivo y la indisciplina del comparatismo. Cadernos de Estudos Culturais, Campo Grande, v.1, n.2, 2009.

. Frutos estranhos: a inespecificidade na estética contemporânea. São Paulo: Rocco, 2014. (Col. Entrecríticas).

HOLLANDA, H. B. de. Esses poetas. Uma antologia dos anos 90. Rio de Janeiro: Aeroplano, 1998.

26 poetas hoje. 6.ed. Rio de janeiro: Aeroplano, 2007.

JAY, M. El modernismo y el abandono de la forma. In: . Campos de fuerza. Buenos Aires: Paidós, 2003.

KRAUSS, R. Sculpture in the expanded field. In: FOSTER, H. The anti.aesthetic: essays on postmodern culture. New York: New York Press, 1983.

LADDAGA, R. Estética de la emergencia. La formación de otra cultura de las artes. Buenos Aires: Adriana Hidalgo, 2006.

LYOTARD, J.-F. Re-escrever a modernidade. In: O inumano. Considerações sobre o tempo. Lisboa: Editorial Estampa, 1997.

MAN, P. de. O ponto de vista da cegueira. Braga; Coimbra; Lisboa: Angelus Novus, Cotovia, 1999.

MARTELO, R.; EIRAS, P. (Trad.) Mallarmé. Crise de versos. Porto: Deriva; Instituto de Literatura Comparada Margarida Llosa, 2012.

NANCY, J.-L. A la escucha. Buenos Aires: Amorrortu, 2007.

PAZ, O. Os filhos do barro. São Paulo: CosacNaify, 2013.

PEDROSA, C. Antonio Candido: a palavra empenhada. São Paulo: Edusp; Niterói: EdUFF, 1994.

Poesia, crítica, endereçamento. In: KIFFER, A. P.; GARRAMUÑO, F. (Org.)

Expansões contemporâneas: literatura e outras formas. Belo Horizonte, EdUFMG, 2015. (Col. Babel). 
PEDROSA, C.; ALVES, I.; JÜDICE, N. Critica de poesia: tendências e questões. Brasil-Portugal. Rio de Janeiro: 7 Letras, 2014.

RANCIÈRE, J. As vozes e os corpos. In: . Políticas da escrita. São Paulo: Editora 34, 1995a. 1995b. Transportes da liberdade. In: Politicas da escrita. São Paulo: Editora 34, . Mallarmé. La politique de la sirène. Paris: Hachette, 2006.

REINHARD, K. Kant with Sade, Lacan with Levinas. Modern Languages Notes, v.110, n.4, 1995 .

SANTIAGO, S. O entre-lugar do discurso latino-americano. In: . Uma literatura nos trópicos. Ensaios sobre dependência cultural. São Paulo: Perspectiva, 1978a.

. O assassinato de Mallarmé. In: Uma literatura nos trópicos. Ensaios sobre dependência cultural. São Paulo: Perspectiva, 1978b. 1989. . Singular e anônimo. In: . Nas malhas da letra. São Paulo: Cia. das Letras,

SCHEIBE, F. (Trad.) Mallarmé. Divagações. Florianópolis: Editora da Universidade Federal de Santa Catarina, 2010.

SISCAR, M. Poetas à beira de uma crise de versos. In: . Poesia e crise. Campinas: Editora da Unicamp, 2010.

. Apresentação. In: CESAR, A. C. Ana Cristina Cesar. Rio de Janeiro: Eduerj, 2011. (Col. Ciranda da Poesia). tor, 2012 .

. Da soberba da poesia: distinção, elitismo, democracia. São Paulo: Lumme Edi-

SÜSSEKIND, F. Até segunda ordem não me risque nada. Os cadernos, rascunhos e a poesia-em-vozes de Ana Cristina Cesar. Rio de Janeiro: Sete Letras, 1995.

. Posfácio. In: Adilia Lopes. Antologia. São Paulo: CosacNaify, 2002.

. Desterritorialização e forma literária. Literatura brasileira e experiência urbana. Literatura e Sociedade, São Paulo, n.8, 2005.

. A imagem em estações - Observações sobre "Margens", de Carlito Azevedo. In: PEDROSA, C.; ALVES, I. (Org.) Subjetividades em devir. Estudos de poesia moderna e contemporânea. Rio de Janeiro: 7 Letras, 2008.

RESUMO - Este artigo avalia a produtividade do uso das noções de "crise" e de "expansão" em algumas leituras da produção poética brasileira a partir dos anos 1980. Tal produtividade é associada a uma desestabilização do discurso crítico em decorrência do enfrentamento da relação entre heterogeneidade e contemporaneidade.

PALAVRAS-CHAVE: Poesia, Crítica, Crise, Heterogeneidade, Expansão.

ABSTRACT - This paper evaluates the usefulness of the terms "crisis" and "expansion" in certain readings of the Brazilian poetic production since the 1980s. Their purported 
usefulness is associated with a destabilization of the critical discourse derived from the face-off between heterogeneity and contemporaneity.

KErWORDs: Poetry, Criticism, Crisis, Heterogeneity, Expansion.

Célia Pedrosa é professora do Departamento de Ciências da Linguagem, Universidade Federal Fluminense (UFFL), Campus do Gragoatá, Rio de Janeiro.

@ - artecelia@gmail.com

Recebido em 10.2.2015 e aceito em 22.2.2015.

${ }^{\text {I }}$ Departamento de Ciências da Linguagem, Universidade Federal Fluminense (UFFL), Rio de Janeiro/RJ, Brasil. 
